\title{
Research on Tourism Development and Protection of Residential Historic Blocks
}

\author{
Li Shan, Yu Xiaoling \\ Xinjiang Economic Management College of Tarim University, Xinjiang in 843300, China
}

Key words: Residential historic blocks; tourism development; tourism

\begin{abstract}
As the society develops, tourism development of historic blocks will be a good form of inheriting and promoting our nation's traditional culture. Nevertheless, with regard to the tourism development situation of residential historic blocks in many places in China, there have been lots of problems in its development and protection, based on which this author of this paper has made a research mainly on tourism development of residential historic blocks and a field investigation on the situation of the historic blocks, from the perspective of community tourism theory. This paper has proposed some development ideas and related suggestions of historic cultural blocks, hoping to provide reference for protection and tourism development of historic blocks.
\end{abstract}

\section{Introduction}

Historic block is also called historical cultural district, which is the material carrier of a city's history and profound cultural deposits. However, in the process of large scales of modern urban constructions, some of the significant constituents of social and cultural resources as well as historic and cultural circumstances of historic blocks have been suffering severe destructions. Meanwhile, with the constant improvement of the public's cultural quality, cultural tourism is becoming popular among tourists day by day due to its unique cultural deposits and specific cultural experience. Historic blocks have a great amount of tourism resource such as cultural relics and historic sites, traditional constructions, and folk custom, which is the symbol of famous historic and cultural city and the cultural exhibition space. A scientific and reasonable tourism development can not only protect precious cultural heritages, promoting the inheritance of excellent traditional culture, but also facilitate the development of local economics, promoting livelihood quality of local residents. A lot of well-protected historic blocks have become famous cultural tourist attractions such as the South Street in Pingyao, Tunxi Old Street in Huangshan city, etc. It has been a commonly focused issue among all sectors of society that how to realize a balance between protection and development of historic blocks by means of scientific and reasonable industry replacement and feature updates. The author of this paper has made probes of tourism development and protection of residential historic blocks, hoping to provide references to the protection and tourism development of historic blocks.

\section{General situation of residential historic blocks}

Residential historic blocks, also called as old urban region, is generally referred to a region in which ancient and old constructions are comparatively more concentrative, which is a kind of 
expression to historic culture. Residential historic blocks usually gather history, culture, education, commerce, and spring as a whole, being the cultural essence of one region. Residential historic blocks have the variety of specific alleys, with every street and alley having its story and history, more or less having some historical relics. Among these historic cultural blocks, some of them are well-structured quadrangle courtyards in which big yards surrounding small yards with porches connecting each other. Actually, its the essence with the characteristics of the Spring City of historic culture, traditional folk customs, and spring pools and gardens.

Due to the distant gap between the present conditions of historic blocks and the demands of modern life, facing with the impact of a large-scale reconstruction of old city, the protection of old city has become more difficult. For many famous historic cultural cities in China, the nominal protection of old city has finally turned out to be destroy, failing in protecting the old city but even inflicting "constructive destroy" to many historic blocks, which has destroyed the blocks' historic feature. Some of the constructions and cultural relics have been destroyed and haven't existed any more due to being long neglected and in disrepair; because of historical or man-made reasons, with the development of society and the increasing of population density, the traditional scene of residential houses and yards have been destroyed by constructing in the yards because of poor quality of houses, too small living area, old-fashioned and obsolete infrastructure in the old city region in Jinan. Moreover, the demolition of traditional blocks by the government has impacted the traditional architectures to some extent.

\section{Problem analysis of tourism development of residential historic blocks}

The property ownership of residential historic cultural blocks is very complicated, and the jurisdiction relations of it refer to many governmental or industrial institutions, basically including three types: private property, public property, company self-managed property. Among them, the construction of private properties is very complex, dividing into three special types of state-owned renting houses, standard private renting houses, and housing-reform houses. The house owners of state-owned renting houses and standard private renting houses have the property right, but they are incapable of requiring lessees to leave their houses, which means they don't have practical right of using. If the property right can't be clearly defined in the process of actual protection and development, there will definitely be all kinds of contradictions which might be obstacles in the process of tourism development.

The primary function of the residential historic cultural blocks is providing convenience for the residents. The majority of traditional residential buildings have the situation of breakage and aging to some extent due to the long term of usage. With the changing of urban functions, because the infrastructure in residential old blocks can't follow the steps of times, there have been a great amount of migrations, reconstructions, and betterments works, which destroying the original appearance of the blocks in structure, enhancing the difficulty in protecting the blocks, meanwhile, it has also influenced the aesthetic feelings, decreasing its value in tourism development, making this kind of tourism exploration resource harder to define.

With regard to partial blocks, in the process of tourism development, in order to improve the scheming efficiency of the scenic spot and unify the construction style, all the common residential houses except a small amount of certificated culture relic protection constructions had been torn down and reconstructed into an archaistic style for the purpose of business development or other purposes. Even there have been some developers constructing a wholesale "fake antiques", adopting 
the way of "reconstructing with maintaining the name" on those certificated cultural preservation buildings in order to pursuing higher economic efficiency as well as greater visual impacts for visitors. For example, in order to forge the "archaistic block of the Minister's childhood", the Huaian government dismantled many old residential houses which have been existing for over a hundred year since the Qing Dynasty and the Republic of China period. The majority of the rest dwellings had been reconstructed after being dismantled, forming a great amount of fake antiques only have decorative meanings but no historic values, which might confuse later generations' understandings to real historical relics. The authenticity of blocks and the continuity of life have been destroyed.

In the process of reconstructing the historic cultural blocks, there would usually be large land agents intervening in, for pursuing more profitable interests, they would generally transform residential houses to commercial constructions so as to gain a high rate of return in rent. Thus, it might destroy the social and cultural circumstance of the previous blocks and distort the traditional way of living. Just as above-mentioned Broad and Narrow Alley in Chengdu, and ancient water town of Xitang, in the process of tourism exploitation the aboriginals were migrated and the blocks were built by people as a totally commercial-based one.

\section{Tourism development idea of residential historic cultural blocks}

What tourists need is specific and unique tourism products, which is the most vital elements for attracting them to consume here instead of there. In the big environment of modern urbanization is progressing, blind constructions and irrational inter-imitations have caused all city styles in China trending to be similar day by day. In the 21st century, people's degree of recognition to local characteristics are lifting and the demands of constructing local culture with unique characteristics according to the context of local history have been generating. Each place has its streams in form all over the country, the construction groups of residential historic cultural blocks has described the trade of the local people's life in the past hundreds and thousands of years. History has become memory here, being sculptured on black bricks and flagstones, which is the material and mental carrier for us human beings to know the history of ourselves as well as to chase back into history, and is also the main base for displaying a city's cultural characteristic. Hence, when making tourism scheme for every valuable historic block, an important factor is to consider the peculiarity of it in the aspects of natural, historical, heritage, and economic inheritance.

"Authenticity" means original and true nature literally. One can imagine that the authenticity of tourism points to the most original and true existence form of tourism culture, instead of the one decorated in a man-made and fictitious way. Authenticity includes the authentic form in historical level and social level. This historical authenticity means that historic blocks should perseverance a certain sum and ratio of material entities according historical information and being real; while social authenticity means that historic blocks should preserve a certain ratio of aboriginals and original lifestyles. Residents in alleys chatting with accent, memorable exhibitions in old stores, fragrance of dishes flowing out of mottled walls, common people in the past living in neighborhood of high officials and noble lords, which have formed one and another vivid pictures of society. Just as the famous expert on famous historic cultural city protection Mr. Ruan Yisan said, "Dismantling one period and reconstructing afterwards must be avoided by all means in tourism schemes, because the historic blocks after being constructed in that way can only reflect the engineer's understanding and intention, although it might be skillful, nevertheless it is not history." 
The nature of tourism is experience. Tourism product itself has invisible nature, which decides the tourists' pursuit for touring experience, so as to say, what tourists consume is not the cultural block itself. Cultural relics and historic sites, as well as lifestyle in historic blocks can only be esteemed as a material carrier supporting tourists' experience. Residential historic cultural blocks carry the city's historical context, and a city's historical connotation is always decided by the historic blocks' imagine characteristics and functional qualities. What tourists pursuing is the touring experience generated in the contact with the feature elements like history, life, folk custom, and art existing in historic blocks, which is so-called deep experiential tourism. Quoted from Joseph's words in his book Experiential Economy to describe the experience of tourism products, we can say the design of tourism products should be on the sate of resources, in the background of environment, with the connotation of culture, with the carrier of facilities, supported by services, and create a unique experience for tourists.

Nowadays tourists couldn't be satisfied with having a hurried and cursory glance at scenic spots, they prefer to have interactions with local residents, so some life elements such as elegant vitality and delight of life have become the indispensable elements in tourism. They are more joyful at experiencing life with local regional cultural characteristics, taking part in activities organized by local communities, immersing in the interactions with local people. Meanwhile, the difficulty of hardly meeting both demands of ecology and tourism has always been the obstacle in tourism. Due to historical reasons, roads in historic cultural blocks are commonly narrow, and the capacity of the blocks is limited, if enlarging the tourists volume blindly, the cultural and ecological environment will be damaged badly. Related enterprises and departments should guide the order in their schemes, design the touring routes scientifically, popularizing ecological ideas to tourists, etc. so as to protect the sustainable and healthy development of tourism of the blocks.

\section{Conclusion}

The truism development and protection of residential historic blocks is not only an gaming approach to heritage and glorify its historic culture, but also one of the experiencing ways of tourism. Nevertheless, with regard to present exploiting situation of residential historic cultural blocks in many places, there have been a lot of problems. The main controversies are centralized on the balance between ecological protection and touring experience in detailed exploitation and implementation. It needs our perseverance of accumulating experience in practice to solve the problem that how to build historic blocks into livable and traveling-appropriated ecological regions based on insuring the principle of historical authenticity and sustainable development of tourism.

\section{Reference:}

[1] Qin Xuxia, He Jiamei. Tourism Development and Protection About Historic Cultural Blocks [J]. Data of Culture and Education, 2006 (04): 73-74

[2] Zhu Dongguo, Xie Binggeng, Li Xiaoqing, Fu Lihua. Deep Exploitation and Research on Historic Cultural Blocks Tourism Products--Take Chengzheng Street in Xiangtan City as Example [J]. Academic Journal of Jishou University, 2010 (03): 126-129

[3] Han Ting. Research on Protective Usage of Residential Historic Cultural Blocks [J]. Global City Geography, 2016 (42): 12-13.

[4] Hu Hongmei. Tourism Exploitation of Historic Cultural Blocks Based on Tourists Experience 
[J]. Economic Research Guide, 2010 (35) 97-99.

[5] Zhang Bairu. Research on Protection and Renewal of Residential Historic Cultural Blocks [D]. Central Academy of Fine Arts (CAFA), 2016. 